\title{
Thermophysical properties of the lanthanide sesquisulfides. IV. Schottky contributions, magnetic, and electronic properties of $\epsilon$-phase $\mathrm{Yb}_{2} \mathrm{~S}_{3}$ and $\mathrm{Lu}_{2} \mathrm{~S}_{3}$
}

\author{
John B. Gruber \\ Department of Physics, San Jose State University, San Jose, California 95192
}

Roey Shaviva) and Edgar F. Westrum, Jr. Department of Chemistry, University of Michigan, Ann Arbor, Michigan 48109

Ramón Burriel

Instituto de Ciencia de Materiales de Aragón, Universidad de Zaragoza-CSIC, 50009 Zaragoza, Spain

Bernard J. Beaudry and Paul E. Palmer

Ames Laboratory, Iowa State University, Ames, Iowa 50011-0020

(Received 4 August 1992; accepted 28 September 1992)

\begin{abstract}
The heat capacities of $\epsilon$-phase $\mathrm{Yb}_{2} \mathrm{~S}_{3}$ and $\mathrm{Lu}_{2} \mathrm{~S}_{3}$ have been determined from 6 to $350 \mathrm{~K}$ and their thermodynamic properties evaluated. The resolution of the Schottky and magnetic properties by evaluation of the lattice heat capacity is shown to be in accord with spectroscopically determined energy levels. The lattice heat capacity of $\mathrm{Yb}_{2} \mathrm{~S}_{3}$ was determined by means of the Komada-Westrum phonon distribution model. Excess heat-capacity contributions were thus evaluated and analyzed as Schottky and magnetic heat capacities. A phase transition associated with magnetic ordering was detected in the heat capacity of $\mathrm{Yb}_{2} \mathrm{~S}_{3}$ near $7 \mathrm{~K}$ with an entropy content of $0.68 R$. The entropies at $298.15 \mathrm{~K}$ are $22.77 R$ and $19.74 R$ for $\mathrm{Yb}_{2} \mathrm{~S}_{3}$ and for $\mathrm{Lu}_{2} \mathrm{~S}_{3}$.
\end{abstract}

\section{INTRODUCTION}

The electronic and magnetic behavior of the $\gamma$-phase lanthanide sesquisulfides have been elucidated in the first three papers in this series ${ }^{1-3}$ by separating the excess heat capacity from the lattice heat capacity by using both the volumetric priority ${ }^{4}$ approach and the Komada-Westrum ${ }^{5}$ approach. The analysis of the crystalline electric field splitting, the Raman and infrared spectra, and magnetic susceptibility are consistent with the resolved thermophysical values for the $\gamma$-phase sesquisulfides.

Lanthanide sesquisulfides including $\mathrm{Ho}, \mathrm{Er}, \mathrm{Tm}, \mathrm{Yb}$, and $\mathrm{Lu}$ adopt $\delta$ - (or D- or $\mathrm{Ho}_{2} \mathrm{~S}_{3}$ )-type or the $\epsilon$ - (or $E$ - or rhombohedral $\mathrm{Al}_{2} \mathrm{O}_{3}$ )-type structurcs. Other structure types which have been reported for these compounds ${ }^{6}$ are not pertinent to this study. Lanthanide sesquichalcogenides $\left(\mathrm{Ln}_{2} \mathrm{Ch}_{3} ; \mathrm{Ln}=\text { lanthanide, } \mathrm{Ch}=\mathrm{S} \text {, Se, and } \mathrm{Te}\right)^{7}$ and systems involving mixed chalcogenides (e.g., $\mathrm{S}$ with $\mathrm{Se}$ or $\mathrm{Te})^{8}$ are of interest particularly from the materials science point of view. Heat capacities of some $\mathrm{Ln}_{2} \mathrm{Ch}_{3}$, $\mathrm{Ln}_{3} \mathrm{Ch}_{4}$ systems and mixed lanthanides with $\mathrm{Ln}_{2} \mathrm{Ch}_{3}$ have also been explored. ${ }^{8-11}$

$\mathrm{Yb}_{2} \mathrm{~S}_{3}$ and $\mathrm{Lu}_{2} \mathrm{~S}_{3}$ crystallize into the $\epsilon$-phase structure. The structure was first observed by Flahaut et al. ${ }^{12}$ and later confirmed by Range and Leeb. ${ }^{13}$ In this structure, the cation is displaced along the ternary axes toward a trigonal face of the $S$ octahedron in such a way that three $M-S$ bonds are shorter than the other three.

${ }^{a}$ Present address: IMI Institute for Research and Development, P.O. Box 10140 Haifa Bay 26111, Israel.
Since $\mathrm{Lu}^{3+}$ has 14 electrons in its $4 f$ orbital and a ${ }^{1} S_{0}$ ground state, $\mathrm{Lu}_{2} \mathrm{~S}_{3}$ exhibits only lattice heat-capacity contributions. $\mathrm{Yb}_{2} \mathrm{~S}_{3}$ with $134 f$ electrons, however, does not have a closed shell and shows both magnetic and Schottky contributions. Moreover, the ${ }^{2} F_{7 / 2}$ ground-state manifold of the cation $\mathrm{Yb}^{3+}$ in the $\epsilon$ phase is subjected to a crystalline electric field that has $C_{2}$ point group symmetry. The manifold is split into four doubly degenerate electronic energy levels. The lattice heat capacity of $\mathrm{Yb}_{2} \mathrm{~S}_{3}$ cannot be determined experimentally in the subambient region and has to be evaluated by a parametric approximation based on the lattice heat capacity of $\mathrm{Lu}_{2} \mathrm{~S}_{3}$. The method is essentially the same as that employed for the lattice heat capacities of $\gamma$-phase lanthanide sesquisulfides based on $\mathrm{La}_{2} \mathrm{~S}_{3}$ and $\mathrm{Gd}_{2} \mathrm{~S}_{3} \cdot{ }^{1-3}$ The heat capacities of $\epsilon$-phase $\mathrm{Yb}_{2} \mathrm{~S}_{3}$ and $\mathrm{Lu}_{2} \mathrm{~S}_{3}$ have been reported between 1.2 and $20 \mathrm{~K} .{ }^{9,10}$

This paper concerns the experimental thermodynamic properties of the two lanthanide sesquisulfides between 6 and $350 \mathrm{~K}$ and the resolution of the Schottky and magnetic contributions of the $\epsilon$-phase $\mathrm{Yb}_{2} \mathrm{~S}_{3}$ compound.

\section{EXPERIMENT}

\section{A. Sample provenance and characterization}

The $\mathrm{Yb}_{2} \mathrm{~S}_{3}$ and $\mathrm{Lu}_{2} \mathrm{~S}_{3}$ samples were prepared at the Ames Laboratory by direct combination of the pure elements in a manner similar to that described by Gschneidner et al. ${ }^{10}$ The lutetium and ytterbium metals used were prepared in the Ames Laboratory, ${ }^{14}$ sublimed 
TABLE I. Lattice parameters and analyzed compositions of $\epsilon$-phase $\mathrm{Yb}_{2} \mathrm{~S}_{3}$ and $\mathrm{Lu}_{2} \mathrm{~S}_{3}\left(R=8.3144 \mathrm{~J} \mathrm{~K}^{-1} \mathrm{~mol}^{-1}\right)$.

\begin{tabular}{|c|c|c|c|c|c|c|c|c|}
\hline \multirow[b]{2}{*}{ Sesquisulfide } & \multicolumn{2}{|c|}{ Lattice parameters $(\AA)$} & \multirow{2}{*}{$\begin{array}{l}\text { S/Ln mole ratio } \\
\text { (by analysis) }\end{array}$} & \multirow{2}{*}{$\begin{array}{c}\nu^{b} \\
\left(\mathrm{~cm}^{3} / \mathrm{mol}\right)\end{array}$} & \multirow{2}{*}{$\begin{array}{c}\rho^{\mathrm{d}} \\
\left(\mathrm{g} / \mathrm{cm}^{3}\right)\end{array}$} & \multirow[b]{2}{*}{$m(\mathrm{~g})^{\mathrm{c}}$} & \multirow[b]{2}{*}{$M\left(\mathrm{~g} \mathrm{~mol}^{-1}\right)$} & \multirow[b]{2}{*}{ Color } \\
\hline & Present study & Ref. 16 & & & & & & \\
\hline $\mathrm{Yb}_{2} \mathrm{~S}_{3}$ & $\begin{array}{l}a_{0}=6.7478 \pm 0.0003^{\mathrm{a}} \\
c_{0}=18.1900 \pm 0.0008\end{array}$ & $\begin{array}{r}6.748 \\
18.191\end{array}$ & $1.502 \pm 0.003$ & 71.993 & 6.1421 & 42.60 & 442.26 & Yellow gold \\
\hline $\mathrm{Lu}_{2} \mathrm{~S}_{3}$ & $\begin{array}{l}a_{0}=6.7220 \pm 0.0005^{\mathrm{a}} \\
c_{0}=18.154 \pm 0.001\end{array}$ & $\begin{array}{r}6.722 \\
18.160\end{array}$ & $1.499 \pm 0.005$ & 71.315 & 6.2556 & 33.434 & 446.12 & Greyish white \\
\hline
\end{tabular}

${ }^{2}$ Hexagonal.

${ }^{\mathrm{b}} V=$ molar volume.

$c m=$ sample mass.

d $\rho=\mathrm{x}$-ray density.

sulfur (99.999\%) was obtained from ASARCO. ${ }^{15}$ After completion of the reaction in the sealed fused silica ampoules, the $\mathrm{Lu}_{2} \mathrm{~S}_{3}$ was further purified by reaction with $\mathrm{H}_{2} \mathrm{~S}$. The ampoules were opened in a helium-filled glove box. The as-formed $\mathrm{Lu}_{2} \mathrm{~S}_{3}$ was ground to 200 mesh powder, cold pressed into pellets at $2.1 \times 10^{8} \mathrm{~Pa}\left(3 \times 10^{4} \mathrm{lbs} /\right.$ $\mathrm{in}^{2}$ ), and heated to $1275^{\circ} \mathrm{C}$ for $50 \mathrm{~h}$ under a dynamic $\mathrm{H}_{2} \mathrm{~S}$ atmosphere. A Debye-Scherrer x-ray diffraction pattern only gave lines of the $\epsilon \mathrm{Lu}_{2} \mathrm{~S}_{3}$ structure. All of the $\mathrm{Lu}_{2} \mathrm{~S}_{3}$ dissolved readily in a $1: 1 \mathrm{HCl}: \mathrm{H}_{2} \mathrm{O}$ solution indicating that oxysulfide was not present.

In the preparation of $\mathrm{Yb}_{2} \mathrm{~S}_{3}$, stoichiometric quantities of $\mathrm{Yb}$ metal and sulfur were sealed into two separate fused silica ampoules. The ampoules were heated slowly to $575^{\circ} \mathrm{C}$ and maintained there until all free sulfur had reacted. The temperature was then slowly increased-over three days- to $850^{\circ} \mathrm{C}$, held there for ten days, and then raised to and held at $900{ }^{\circ} \mathrm{C}$ for two more days. Both ampoules contained hard chunks of yellow-gold colored $\epsilon$-phase $\mathrm{Yb}_{2} \mathrm{~S}_{3}$ at the end of this process. Heating $\mathrm{Yb}_{2} \mathrm{~S}_{3}$ under $\mathrm{H}_{2} \mathrm{~S}$ was not required. Chemical analysis of a random sample gave $\mathrm{YbS}_{1.5 \pm 0.003}$, indicating the intended composition of $\mathrm{YbS}_{1.500}$ had been achieved within the accuracy of the analysis. A complete description of the chemical analysis method is given in the first paper of this series. An $x$-ray diffraction pattern gave only lines of $\epsilon$-phase $\mathrm{Yb}_{2} \mathrm{~S}_{3}$. No acid insoluble residue remained after treatment with 1:1 $\mathrm{HCl}: \mathrm{H}_{2} \mathrm{O}$. Precision lattice parameters were determined for both $\epsilon-\mathrm{Lu}_{2} \mathrm{~S}_{3}$ and $\epsilon-\mathrm{Yb}_{2} \mathrm{~S}_{3}$ from DebyeScherrer $\mathrm{x}$-ray patterns taken at $295 \mathrm{~K}$ by measuring the theta values of the doublets in the back reflection and applying a Nelson-Riley extrapolation function to the data. Lattice parameters determined in this study are given in Table I along with literature values. ${ }^{16}$

\section{B. Automated adiabatic calorimetry}

Two gold-plated, oxygen-free, high-conductivity (OFHC) copper calorimeters (laboratory designation $\mathrm{W}-61$ and $\mathrm{W}-\mathrm{AB}$ ) were employed in the two measurements. The $\mathrm{Lu}_{2} \mathrm{~S}_{3}$ sample was determined in the W-61 calorimeter, which is especially equipped with two pairs of perforated, spring-loaded, copper sleeves soldered to the heater-thermometer well to hold the sample pellets. The heat capacity of the $\mathrm{Yb}_{2} \mathrm{~S}_{3}$ (Ref. 16) sample was determined in the W-AB calorimeter. After loading (and for $\mathrm{Lu}_{2} \mathrm{~S}_{3}$, soldering the cover in place), the calorimeters were evacuated and approximately $2.0 \mathrm{kPa}$ (at about $300 \mathrm{~K}$ ) helium gas was added to facilitate rapid thermal equilibration (see also Table I). The data were taken in the Mark X calorimetric cryostat, an improved version of the Mark II cryostat described elsewhere, together with relevant operating techniques. ${ }^{17,18}$ Data acquisition was computer assisted. The temperatures were measured with a Leeds and Northrup platinum resistance thermometer calibrated at the National Bureau of Standards (NBS). All other crucial measurements were similarly referenced to NBS calibrations.

\section{Optical spectroscopy}

The material used to obtain the absorption spectrum of $\mathrm{Yb}_{2} \mathrm{~S}_{3}$ was prepared by the method of Henderson et al. ${ }^{19}$ The samples contained less than $100 \mathrm{ppm}$ atomic oxygen and displayed the Debye-Scherrer $\mathrm{x}$-ray pattern for $\epsilon$-phase $\mathrm{Yb}_{2} \mathrm{~S}_{3}$. Based on wet chemical analysis, the compounds can be represented as $\mathrm{YbS}_{1.5 \pm 0.003}$. We had no success in growing $\mathrm{YbS}_{1.5}$ single crystals from the melt. Even with an appreciable sulfur vapor pressure within sealed capsules, it was not possible to keep some of the trivalent ytterbium from being reduced. The melted ingots were black with very small crystallites found scattered throughout the highly fractured material.

To obtain the absorption spectrum of $\mathrm{Yb}_{2} \mathrm{~S}_{3}$, stoichiometric powder was mixed with an optically transparent inert gel to produce "mull" samples. The spectra were observed with a Cary Model $14 \mathrm{R}$ at $90 \mathrm{~K}$ and room temperatures. Hot bands of the ${ }^{2} F_{5 / 2}$ multiplet manifold observed at $1.0 \mu \mathrm{m}$ indicate that the ground state ${ }^{2} F_{7 / 2}$ has crystalfield electronic energy levels at $0,155,285$, and $380 \mathrm{~cm}^{-1}$. Each level is twofold degenerate. Since there are more crystal-field parameters associated with $C_{2}$ symmetry than experimental energy levels associated with the ${ }^{2} F_{7 / 2}$ and ${ }^{2} F_{5 / 2}$ multiplet manifolds, we were not able to obtain a 
TABLE II. Experimental heat capacities of $\epsilon$-phase $\mathrm{Yb}_{2} \mathrm{~S}_{3}$ and $\mathrm{Lu}_{2} \mathrm{~S}_{3}$ $\left(R=8.3144 \mathrm{~J} \mathrm{~K}^{-1} \mathrm{~mol}^{-1}\right)$.

\begin{tabular}{cc}
\hline$T / \mathrm{K}$ & $C_{p, m} / R$ \\
\hline
\end{tabular}

E-phase ytterbium sesquisulfide $\left(\mathrm{Yb}_{2} \mathrm{~S}_{3}, M=442.26 \mathrm{~g} \mathrm{~mol}^{-1}\right)$

Series I

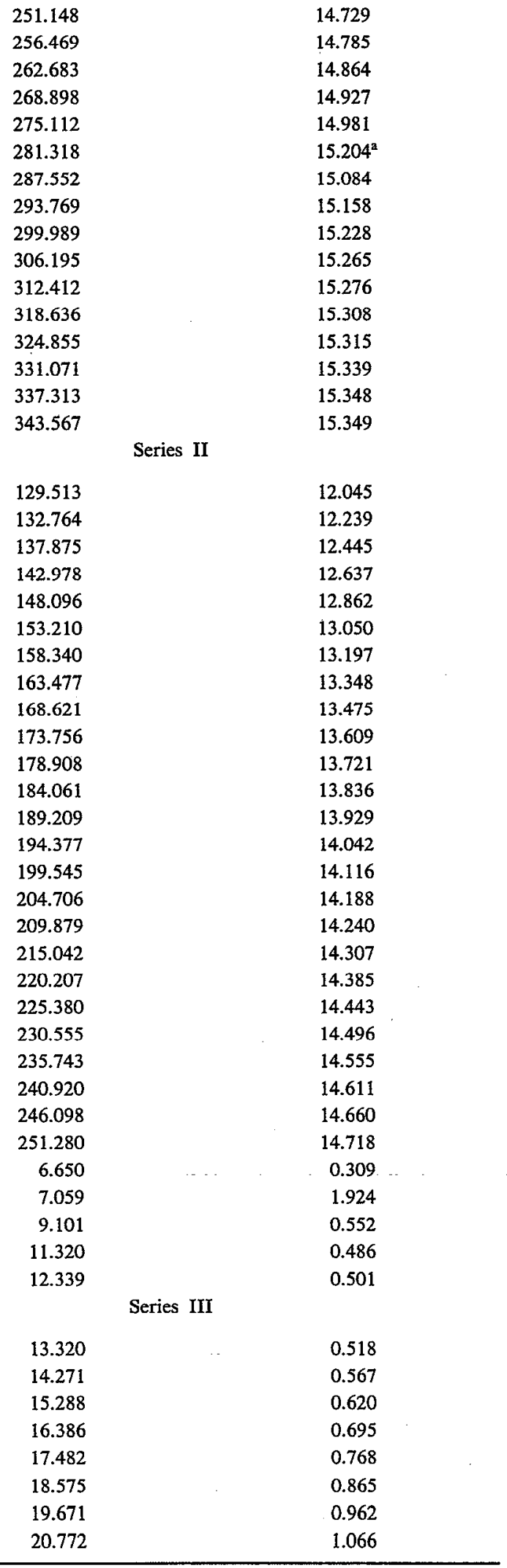

TABLE II. (Continued.)

\begin{tabular}{|c|c|}
\hline$T / K$ & $C_{p, m} / R$ \\
\hline \multicolumn{2}{|c|}{ Series IV } \\
\hline 7.109 & 0.996 \\
\hline 8.598 & 0.558 \\
\hline 10.000 & 0.508 \\
\hline 11.071 & 0.484 \\
\hline 12.095 & 0.497 \\
\hline 13.069 & 0.511 \\
\hline 14.023 & 0.554 \\
\hline 14.961 & 0.603 \\
\hline 15.981 & 0.666 \\
\hline 17.080 & 0.742 \\
\hline 18.174 & 0.827 \\
\hline
\end{tabular}

Series V

6.743

0.675

0.653

0.636

0.645

0.560

0.502

0.501

0.578

0.691

0.826

0.959

1.101

1.247

1.399

1.563

1.731

1.904

2.100

2.311

2.558

$2.647^{\mathrm{a}}$

$3.223^{\mathrm{a}}$

3.321

3.609

3.873

4.187

4.539

4.512

4.863

5.227

5.597

5.968

6.363

6.785

7.198

$7.527^{\mathrm{a}}$

7.977

8.392

8.805

9.210

9.570

9.923

10.253

10.600

10.918

11.245

11.527 
TABLE II. (Continued.)

\begin{tabular}{|c|c|}
\hline$T / \mathrm{K}$ & $C_{p, m} / R$ \\
\hline 124.348 & 11.754 \\
\hline 128.939 & 11.979 \\
\hline 133.515 & 12.280 \\
\hline 138.116 & 12.450 \\
\hline \multicolumn{2}{|c|}{$\begin{array}{l}\epsilon \text {-phase lutetium sesquisulfide }\left(\mathrm{Lu}_{2} \mathrm{~S}_{3}, M=446.12 \mathrm{~g} \mathrm{~mol}^{-1}\right) \\
\text { Series I }\end{array}$} \\
\hline 7.46 & 0.033 \\
\hline 8.04 & 0.045 \\
\hline 8.46 & 0.055 \\
\hline 8.90 & 0.066 \\
\hline 9.35 & 0.081 \\
\hline 9.79 & 0.095 \\
\hline 10.24 & 0.113 \\
\hline 10.64 & 0.128 \\
\hline 11.08 & 0.148 \\
\hline 11.59 & 0.173 \\
\hline 12.11 & 0.199 \\
\hline 12.67 & 0.228 \\
\hline 13.24 & 0.265 \\
\hline 13.85 & 0.300 \\
\hline 14.48 & 0.352 \\
\hline 15.13 & 0.404 \\
\hline 15.83 & 0.460 \\
\hline 16.55 & 0.522 \\
\hline 29.85 & 1.958 \\
\hline 31.25 & 2.121 \\
\hline 32.72 & 2.293 \\
\hline 34.26 & 2.470 \\
\hline 35.89 & 2.654 \\
\hline 37.59 & 2.845 \\
\hline 39.37 & 3.046 \\
\hline 41.24 & 3.258 \\
\hline 43.21 & 3.475 \\
\hline 45.28 & 3.710 \\
\hline 46.89 & 3.885 \\
\hline 49.04 & 4.111 \\
\hline 51.40 & 4.370 \\
\hline 53.88 & 4.625 \\
\hline 56.49 & 4.901 \\
\hline 59.23 & 5.183 \\
\hline 62.10 & 5.502 \\
\hline 65.12 & 5.798 \\
\hline 68.31 & 6.087 \\
\hline 128.42 & 10.444 \\
\hline 133.50 & 10.689 \\
\hline 138.59 & 10.916 \\
\hline 143.69 & 11.132 \\
\hline 148.79 & 11.327 \\
\hline 153.92 & 11.500 \\
\hline 159.04 & 11.670 \\
\hline 164.17 & 11.864 \\
\hline 169.30 & 12.019 \\
\hline 174.45 & 12.122 \\
\hline 179.59 & 12.285 \\
\hline 184.74 & 12.388 \\
\hline \multicolumn{2}{|c|}{ Series II } \\
\hline 170.33 & 11.986 \\
\hline 175.28 & 12.156 \\
\hline 180.42 & 12.314 \\
\hline 185.57 & 12.454 \\
\hline 190.72 & 12.542 \\
\hline 257.87 & 13.577 \\
\hline 263.05 & 13.658 \\
\hline
\end{tabular}

TABLE II. (Continued.)

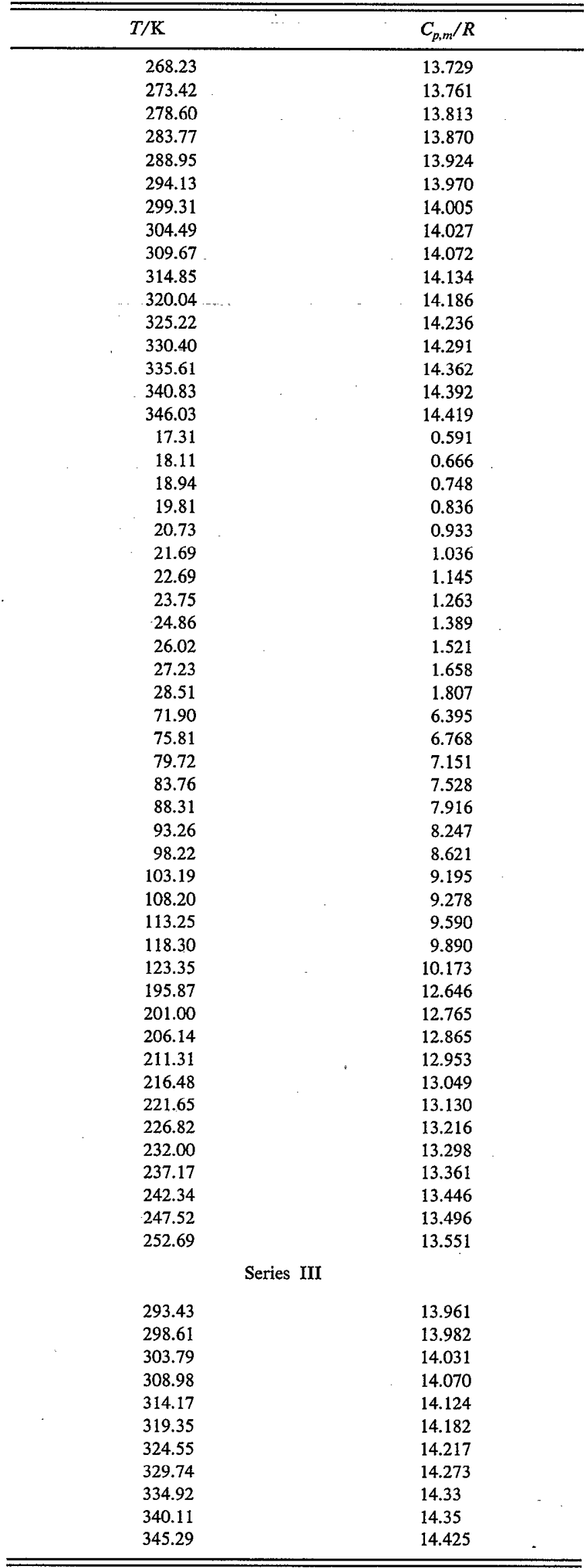

${ }^{a}$ Not included in values on which smoothed curve (Fig 1) is based. 


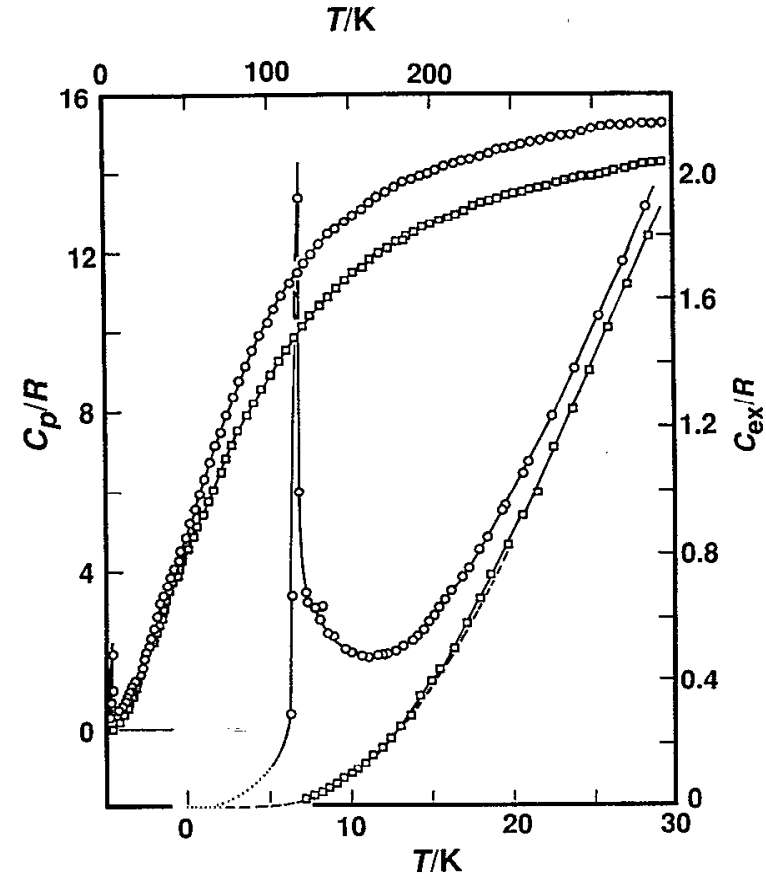

FIG. 1. $C_{p} \epsilon$-phase $\mathrm{Yb}_{2} \mathrm{~S}_{3}-O$-and $\epsilon$-phase $\mathrm{Lu}_{2} \mathrm{~S}_{3} \uplus$. The data of Gschneidner et al. (Ref. 10) are shown as ---.

unique theoretical crystal-field splitting using the latticesum method described in Ref. 2.

\section{RESULTS AND DISCUSSION}

The expcrimental heat-capacity data for $\mathrm{Yb}_{2} \mathrm{~S}_{3}$ and $\mathrm{Lu}_{2} \mathrm{~S}_{3}$ are presented in Table II and plotted in Fig. 1. Smoothed heat capacities and thermodynamic functions at selected temperatures are presented in Table III. The standard deviation in these measurements is less than $\pm 0.1 \%$ above $20 \mathrm{~K}$. Between 6 and $20 \mathrm{~K}$, the deviations decrease gradually from about $\pm 4 \%$ to $\pm 0.1 \%$ at $20 \mathrm{~K}$.

The Komada-Westrum characteristic temperature $\left(\Theta_{\mathrm{KW}}\right)$ was calculated for $\epsilon$-phase $\mathrm{Lu}_{2} \mathrm{~S}_{3}$ on the assumption that no excess contributions are present in the experimental data. ${ }^{5}$ The lattice heat-capacity contribution of $\epsilon$-phase $\mathrm{Yb}_{2} \mathrm{~S}_{3}$ was then calculated with the LEM-3 computer program using input coefficients calculated in the same manner as those for $\gamma$-phase compounds, but extrapolating from $\mathrm{Lu}_{2} \mathrm{~S}_{3}$ as a reference point. ${ }^{2,3,5}$ Since only one reference point was available in the $\epsilon$ phase, it was assumed that the coefficients vary similarly to those in the $\gamma$-phase lanthanide sesquisulfides, i.e., that the same dependence on atomic number used for the coefficients in the $\gamma$-phase (Fig. 3 of Ref. 3) are used for the $\epsilon$ phase.

The variation in $\Theta_{\mathrm{kw}}$ for $\mathrm{Lu}_{2} \mathrm{~S}_{3}(82.3 \mathrm{~K})$ is shown in Fig. 2. The value calculated for $\mathrm{Yb}_{2} \mathrm{~S}_{3}, \Theta_{\mathrm{KW}}=89.1 \mathrm{~K}$ has been used to obtain the excess heat-capacity contributions to $\mathrm{Yb}_{2} \mathrm{~S}_{3}$ which are shown in Fig. 3 together with the Schottky contribution based on the analysis of the optical
TABLE III. Smoothed heat capacities and derived thermodynamic properties $\left(R=8.3144 \mathrm{~J} \mathrm{~K}^{-1} \mathrm{~mol}^{-1}\right)$.

\begin{tabular}{|c|c|c|c|c|}
\hline & $C_{p, m}$ & $S_{m}^{0}-S_{m}^{0}(0 \mathrm{~K})$ & $H_{m}^{0}-H_{m}^{0}(0 \mathrm{~K})$ & $\overline{\Phi_{m}^{0}}$ \\
\hline$T / \mathrm{K}$ & $R$ & $R$ & $R \cdot K$ & $R$ \\
\hline \multicolumn{5}{|c|}{$\epsilon$-phase ytterbium sesquisulfide $\mathrm{Yb}_{2} \mathrm{~S}_{3}, M=442.26 \mathrm{~g} \mathrm{~mol}^{-1}$} \\
\hline 0.0 & 0.0 & 0.0 & 0.0 & 0.0 \\
\hline 5.0 & 0.094 & 0.022 & 0.110 & 0.0 \\
\hline 10.0 & 0.493 & 0.546 & 4.74 & 0.072 \\
\hline 15.0 & 0.609 & 0.755 & 7.34 & 0.266 \\
\hline 20.0 & 0.991 & 0.977 & 11.25 & 0.414 \\
\hline 25.0 & 1.512 & 1.2528 & 17.47 & 0.554 \\
\hline 30.0 & 2.096 & 1.580 & 29.26 & 0.605 \\
\hline 35.0 & 2.715 & 1.949 & 38.49 & 0.849 \\
\hline 40.0 & 3.352 & 2.353 & 53.65 & 1.012 \\
\hline 45.0 & 3.989 & 2.784 & 72.00 & 1.184 \\
\hline 50.0 & 4.625 & 3.238 & 93.54 & 1.367 \\
\hline 60.0 & 5.920 & 4.195 & 146.27 & 1.757 \\
\hline 70.0 & 7.155 & 5.201 & 211.66 & 2.177 \\
\hline 80.0 & 8.294 & 6.232 & 289.01 & 2.619 \\
\hline 90.0 & 9.293 & 7.268 & 377.07 & 3.078 \\
\hline 100.0 & 10.153 & 8.293 & 474.41 & 3.549 \\
\hline 110.0 & 10.890 & 9.296 & 579.7 & 4.026 \\
\hline 120.0 & 11.523 & 10.271 & 691.8 & 4.506 \\
\hline 130.0 & 12.068 & 11.216 & 809.9 & 4.986 \\
\hline 140.0 & 12.534 & 12.128 & 932.9 & 5.464 \\
\hline 150.0 & 12.927 & 13.006 & 1060.3 & 5.937 \\
\hline 160.0 & 13.255 & 13.851 & 1191.2 & 6.406 \\
\hline 170.0 & 13.526 & 14.663 & 1325.2 & 6.868 \\
\hline 180.0 & 13.753 & 15.443 & 1461.6 & 7.323 \\
\hline 190.0 & 13.943 & 16.20 & 1600.1 & 7.778 \\
\hline 200.0 & 14.107 & 16.92 & 1740.4 & 8.218 \\
\hline 210.0 & 14.251 & 17.61 & 1882.2 & 8.647 \\
\hline 220.0 & 14.380 & 18.27 & 2025.4 & 9.064 \\
\hline 230.0 & 14.496 & 18.92 & 2169.8 & 9.486 \\
\hline 240.0 & 14.605 & 19.53 & 2315.3 & 9.883 \\
\hline 250.0 & 14.711 & 20.13 & 2461.9 & 10.282 \\
\hline 260.0 & 14.818 & 20.71 & 2609.5 & 10.673 \\
\hline 270.0 & 14.926 & 21.27 & 2758.0 & 11.054 \\
\hline 280.0 & 15.03 & 21.82 & 2908.0 & 11.434 \\
\hline 290.0 & 15.13 & 22.35 & 3058.8 & 11.802 \\
\hline 298.15 & 15.20 & 22.77 & 3182.5 & 12.096 \\
\hline 300.0 & 15.22 & 22.86 & 3210.6 & 12.158 \\
\hline 325.0 & 15.32 & 24.08 & 3592.6 & 13.026 \\
\hline 350.0 & 15.37 & 25.22 & 3976.2 & 13.859 \\
\hline \multicolumn{5}{|c|}{$\epsilon$-phase lutetium sesquisulfide $\mathrm{Lu}_{2} \mathrm{~S}_{3}, M=446.12 \mathrm{~g} \mathrm{~mol}^{-1}$} \\
\hline 0.0 & 0.0 & 0.0 & 0.0 & 0.0 \\
\hline 10.0 & 0.103 & 0.033 & 0.250 & 0.008 \\
\hline 15.0 & 0.392 & 0.123 & 1.399 & 0.029 \\
\hline 20.0 & 0.857 & 0.296 & 4.468 & 0.073 \\
\hline 25.0 & 1.404 & 0.545 & 10.100 & 0.141 \\
\hline 30.0 & 1.978 & 0.852 & 18.551 & 0.233 \\
\hline 40.0 & 3.115 & 1.578 & 44.060 & 0.476 \\
\hline 50.0 & 4.209 & 2.390 & 80.67 & 0.777 \\
\hline 60.0 & 5.270 & 3.252 & 128.11 & 1.117 \\
\hline 70.0 & 6.259 & 4.140 & 185.82 & 1.485 \\
\hline 80.0 & 7.165 & 5.036 & 253.01 & 1.873 \\
\hline 90.0 & 7.985 & 5.928 & 328.83 & 2.274 \\
\hline 100.0 & 8.724 & 6.808 & 412.44 & 2.683 \\
\hline 120.0 & 9.981 & 8.514 & 600.0 & 3.514 \\
\hline 140.0 & 10.973 & 10.130 & 809.9 & 4.345 \\
\hline 160.0 & 11.733 & 11.647 & 1037.3 & 5.164 \\
\hline 180.0 & 12.303 & 13.064 & 1278.0 & 5.964 \\
\hline 200.0 & 12.738 & 14.383 & 1528.6 & 6.741 \\
\hline 220.0 & 13.091 & 15.61 & 1786.9 & 7.492 \\
\hline 240.0 & 13.392 & 16.77 & 2051.8 & 8.217 \\
\hline 260.0 & 13.645 & 17.85 & 2322.3 & 8.917 \\
\hline 280.0 & 13.841 & 18.87 & 2597.3 & 9.592 \\
\hline 298.15 & 13.987 & 19.74 & 2849.7 & 10.183 \\
\hline 300.0 & 14.001 & 19.83 & 2875.6 & 10.243 \\
\hline 320.0 & 14.162 & 20.74 & 3157.2 & 10.870 \\
\hline 350.0 & 14.507 & 22.02 & 3587.0 & 11.772 \\
\hline
\end{tabular}




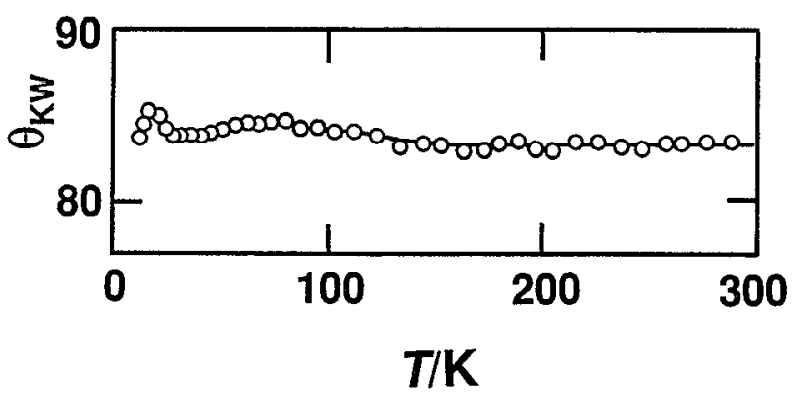

FIG. 2. $\Theta_{\mathrm{KW}}$ for $\epsilon$-phase $\mathrm{Lu}_{2} \mathrm{~S}_{3}$.

spectra. The agreement shown in Table IV between the calorimetrically determincd and the spectroscopically ascertained electronic heat capacity is good. Although an independent evaluation of the lattice contribution might also have been made by the volumetric priority method, ${ }^{1}$ the preceding paper in this series ${ }^{3}$ has demonstrated convincingly that - despite differences in approach - the agreement is excellent.

In the vicinity of $7 \mathrm{~K}$, a magnetic transition is found. Resolution of the transition indicated a $\Delta_{\mathrm{trs}} S^{0}$ about $0.68 R$. This value agrees very well with the entropy for the magnetic ordering of $\mathrm{Yb}^{3+}$ with effective spin $S=1 / 2$ in a crystal-field split ground state that is doubly degenerate.

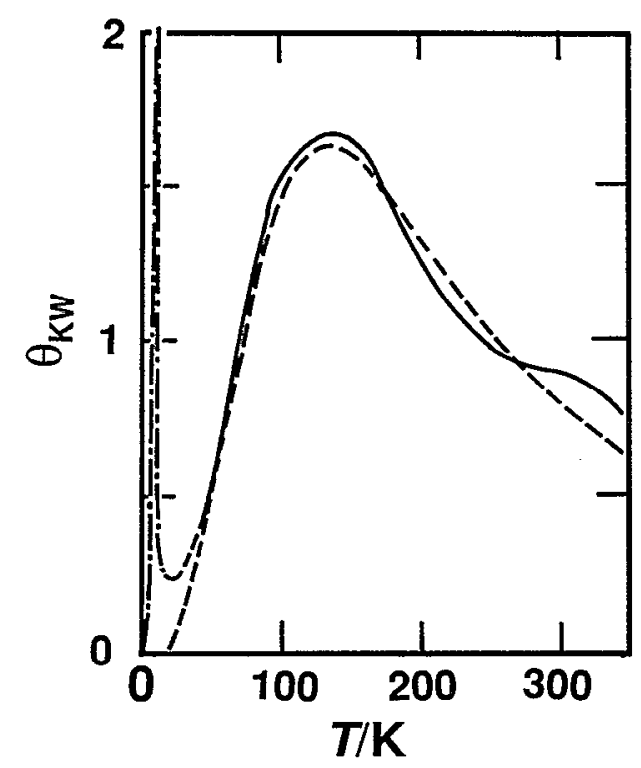

FIG. 3. Excess heat capacities of $\epsilon$-phase $\mathrm{Yb}_{2} \mathrm{~S}_{3}$. Calorimetric-, spectroscopic---, and magnetic- - -contributions.
TABLE IV. Schottky levels, ground state manifold, for $\epsilon$-phase $\mathrm{Yb}_{2} \mathrm{~S}_{3}$.

\begin{tabular}{llc}
\hline \hline $\begin{array}{l}\text { Compound } \\
\left(\text { term } \theta_{\mathrm{KW}}\right)\end{array}$ & $\begin{array}{c}\text { Method of } \\
\text { determination }\end{array}$ & Energy $\left(\mathrm{cm}^{-1}\right)$ and degeneracy $(n)$ \\
\hline$\epsilon-\mathrm{Yb}_{2} \mathrm{~S}_{3}$ & Optical spectra & $0(2), 155(2), 285(2), 380(2)$ \\
$\mathrm{Yb}^{3+}\left({ }^{2} \mathrm{~F}_{7 / 2}\right)$ & Excess $C_{p}(\mathrm{KW})$ & $0(2), 155(2), 285(2), 380(2)$ \\
$\theta_{\mathrm{KW}}=89.12$ & \\
$\epsilon-\mathrm{Lu}_{2} \mathrm{~S}_{3}, \mathrm{Lu}^{3+}\left({ }^{1} S_{0}\right), \theta_{\mathrm{KW}}=82.3$ & \\
\hline \hline
\end{tabular}

\section{ACKNOWLEDGMENTS}

We thank Guy Metz for help with the measurements on $\mathrm{Lu}_{2} \mathrm{~S}_{3}$ and Sithumini Peiris for help in the evaluation of data and preparation of figures. Financial support from CICYT, project number MAT89-0531 is gratefully acknowledged. Work funded in part by the National Science Foundation. Sample preparation and characterization carried out at the Ames Laboratory was supported by the Office of Basic Energy Sciences, Department of Energy, under Contract No. W-7405-ENG-82.

${ }^{1}$ E. F. Westrum, Jr., R. Burriel, J. B. Gruber, P. E. Palmer, B. J. Beaudry, and W. A. Plautz, J. Chem. Phys. 91, 4838 (1989).

${ }^{2}$ J. B. Gruber, R. Burriel, E. F. Westrum, Jr., W. Plautz, G. Metz, Xiao-Xia Ma, B. J. Beaudry, and P. E. Palmer, J. Chem. Phys. 95, 1964 (1991).

${ }^{3}$ R. Shaviv, E. F. Westrum, Jr., J. B. Gruber, B. J. Beaudry, and P. E. Palmer, J. Chem. Phys. 96, 6149 (1992).

${ }^{4}$ E. F. Westrum, Jr., Pure Appl. Chem. 55, 539 (1983).

${ }^{5}$ N. Komada, Ph.D. thesis, University of Michigan, Ann Arbor, MI, 1985.

${ }^{6} \mathrm{~J}$. Flahaut, in Handbook on the Physics and Chemistry of Rare Earths, edited by K. A. Gschneidner, Jr. and L. Eyring (North Holland, Amsterdam, 1978), Vol. 4, p. 429.

${ }^{7}$ V. V. Tikhonov and I. A. Smirnov, Sov. Phys. Solid State 13, 2296 (1971).

${ }^{8}$ E. Bucher, K. Andrés, F. J. Di Salvo, J. P. Maita, A. C. Gossard, A. S. Cooper, and G. W. Hull, Jr., Phys. Rev. B 11, 500 (1975).

${ }^{9}$ S. M. A. Taher, J. C. Ho, J. B. Gruber, B. J. Beaudry, and K. A. Gschneidner, Jr., The Rare Earths in Modern Science and Technology (Plenum, New York, 1980), Vol. 2, p. 423.

${ }^{10}$ K. A. Gschneidner, Jr., B. J. Beaudry, T. Takeshita, S. S. Eucker, S. M. A. Taher, J. C. Ho, and J. Gruber, Phys. Rev. B 24, 7187 (1981).

${ }^{11}$ J. C. Ho, S. M. A. Taher, G. B. King, J. B. Gruber, B. J. Beaudry, and K. A. Gschneidner, Jr., J. Phys. 39, C6 (1978).

${ }^{12}$ J. Flahaut, L. Domange, M. Guittard, and M. P. Pardo, Bull. Soc. Chim. France 7, 326 (1965).

${ }^{13}$ K. J. Range and R. Leeb, Z. Naturforsch. Teil B 30, 637 (1975).

${ }^{14}$ B. J. Beaudry and K. A. Gschneidner, Jr., in Handbook on the Physics and Chemistry of Rare Earths, edited by $\mathrm{K}$. A. Gschneidner, Jr. and L. Eyring (North Holland, Amsterdam, 1978), Vol. 1, p. 173.

${ }^{15}$ American Smelting and Refining Co., Denver, CO.

${ }^{16}$ A. W. Sleight and C. T. Prewitt, Inorg. Chem. 7, 2282 (1968).

${ }^{17}$ E. D. West and E. F. Westrum, Jr., in Experimental Thermodynamics, edited by J. P. McCullough and D. W. Scott (Butterworths, London, 1968), Vol. 1, p. 333.

${ }^{18} \mathrm{E}$. F. Westrum, Jr., in Thermochemistry and its Applications to Chemical and Biochemical Systems, edited by M. A. V. Ribciro da Silva (Reidel, Dordrecht, 1984), p. 754.

${ }^{19}$ J. R. Henderson, M. Muramoto, E. Loh, and J. B. Gruber, J. Chem. Phys. 47, 3347 (1967). 